\title{
Diabetic Foot Management: How Could a Procedural Pathway Improve the Surgical Outcome?
}

\author{
Belgaid V, MD, Courtin C, MD, Desmarchelier R, MD, Fessy M, PhD, Besse JL, PhD \\ Department of Orthopaedic and Traumatology, Centre Hospitalier Lyon-Sud, Pierre-Benite, France \\ This is an open-access article distributed under the terms of the Creative Commons Attribution License, which permits unrestricted use, \\ distribution, and reproduction in any medium, provided the original work is properly cited \\ Date of submission: 15 th February 2020 \\ Date of acceptance: 26th July 2020
}

\begin{abstract}
Introduction: Diabetic foot ulcer is the main aetiology for non-traumatic amputation, which is a major public health care concern. A multidisciplinary approach in the management of this pathology has been shown to improve the surgical outcome. However, there are little data available on the tools we can use to pursue this multidisciplinary approach. The main goal of this cross-sectional study was to find out whether the implementation of a specific management pathway could improve the treatment outcome in the treatment of diabetic foot.

Materials and Methods: From 2012 to 2014, we consecutively recruited patients with diabetic foot referred to Orthopaedic surgery department of our university for surgical opinion. A specific diabetic foot pathway was introduced in 2013. One group of patients who were treated with previous method were evaluated retrospectively. Another group of patients who were treated after implementation of the pathway were evaluated prospectively. We compared treatment outcome between the two groups.

Results: We included 51 patients. Amputation rate was similar both the groups: $74 \%$ in the retrospective group not using the new pathway versus $73 \%$ in a prospective group that used the new pathway. Revision surgery was $39 \%$ in the retrospective group and $14 \%$ in the prospective group $(\mathrm{p}=0.05)$.

Conclusion: We recommend the use of this simple and costeffective pathway to guide the interdisciplinary management of diabetic foot. A prospective study with more subjects would provide a better overview of this management pathway.
\end{abstract}

Keywords:

amputation, diabetes, foot, orthopaedic surgery, pathway

\section{INTRODUCTION}

As the prevalence of diabetes is increasing in many countries like France ${ }^{1}$, Malaysia ${ }^{2}$, and $\mathrm{USA}^{3}$, foot complications become a major public health-care problem. Between $15 \%, 4,5$ to $25 \%{ }^{6,7}$ of diabetic patients may develop foot ulcers at some point in their lifetime. Diabetic foot is the main aetiology of non-traumatic amputations ${ }^{8}$. In 2003, the incidence of lower limb amputations related to diabetes in France was $349 / 100,000^{9}$.

A recent study in Malaysia reported that among patients with infected diabetic foot, a longer duration of disease, raised total white blood cell count and history of more than three limb-salvage surgery were the predictors for major lower limb amputation ${ }^{10}$. This entity needs global attention and multidisciplinary management involving both the medical and para-medical teams. International recommendations such as the guidelines from the Infectious Diseases Society of America (IDSA), and the International Working Group on Diabetic Foot (IWGDF) are readily available, providing consensus on various aspects of the diagnosis and management of diabetic foot problems ${ }^{11-13}$. However, data about how the clinical teams should work together are scanty in recent medical literature.

In our institution, Orthopaedic surgeons can directly communicate with specialists from the endocrinology unit, vascular surgeons, and infection disease specialists since we are the reference centre for bone and joint infections of the region. Various imaging modalities (radiography, CT, MRI, Doppler ultrasonography) and transcutaneous oxygen pressure measurement $\left(\mathrm{TcPO}_{2}\right)$ facility are available.

Nonetheless, there are still concerns on the overall management of patients with diabetic foot due to heterogeneity of the condition. Referrals for surgical opinion could come from several sources: emergency medicine unit, endocrinology unit, diabetes ward, other local hospitals, and

Corresponding Author: Vincent Belgaid, Department of Orthopaedic and Traumatology Surgery, Centre Hospitalier Lyon-Sud, 165 Chemin du Grand Revoyet, 69310 Pierre-Benite, France

Email: vincent.belgaid@chu-lyon.fr 
general practitioners. With no unified strategy in the management of the condition, it may be difficult to comply with all the guidelines. We have to make sure that the medical treatment is optimal: acute diabetic foot should be considered as a medical rather than a surgical emergency, and whenever appropriate the infection should be controlled with high doses of intravenous antibiotics. Infected diabetic foot would require urgent assessment by a multidisciplinary team ${ }^{14}$, since this is the main underlying factor that precedes lower extremity amputation and re-amputation ${ }^{15}$. In addition to general clinical examination, additional para-clinical examinations should be performed to assess neuropathy, vascular insufficiency and other sources of infection before planning the surgery.

Even though the Orthopaedic surgeon generally play the main role in the management of patients who require limb amputation $^{16}$, opinion of the vascular surgeons is important. Re-vascularisation procedure may be offered first to reduce the risk of complications such as re-amputation. In our hospital, either a general Orthopaedic surgeon or a foot surgeon would attend to referrals on diabetic foot.

We hypothesised that the implementation of a specific management pathway would improve the surgical outcome of patients with acute problems related to diabetic foot. The main goal of this study was to measure the rates of amputation and revision surgery for this condition. We undertook this cohort study to compare outcomes in patients who went through our management pathway and those who did not.

\section{MATERIALS AND METHODS}

From November 1, 2012 to October 31, 2014 we included consecutively patients diagnosed with diabetic foot who were referred to the Orthopaedic surgery department of our University for opinion. These requests could come from our emergency medicine unit, endocrinology unit, diabetes ward, other local hospitals, and general practitioners. We excluded patients that did not require urgent surgical managements (preventive surgery, Charcot foot), non-diabetic affections, and patients with post-operative infections. The diabetic foot management pathway (Fig. 1) was introduced on 1st November 2013. It was circulated to all the clinical departments in our institution. Information of the patient has to be filled on to a digital form (Fig. 2) by the requesting practitioner before the case can be referred for a surgical opinion. Plain radiographs and photographs of the affected foot condition should also be provided. Some basic information and guidelines were provided on the form, but the preliminary diagnosis and tentative surgical procedure would be provided by a senior surgeon specialised in foot surgery $^{13}$. The patient would subsequently be examined and evaluated by a surgeon from our team (resident or specialist). If necessary, further investigations would be conducted.
The study covered in two periods: for the year before implementation of the pathway, we retrospectively recruited a group of patients and assigned them as the "retrospective group", while for year following the introduction of the pathway, we recruited patients prospectively and assign them as the "prospective group". A total of 51 patients (38 men, $75 \%$ ) with a mean age of 69 years $( \pm 12$, range 26-94 years) were recruited. Twenty-three of them were in the retrospective group (recruited from November 1, 2012 to October 31, 2013), and 28 were in the prospective group (recruited from November 1, 2013 - October 31, 2014).

Based on patient's personal records, we extracted demographic data and clinical information that included: onset of symptom, time to admission, time to surgical opinion request, interval between request for surgical opinion and definitive recommendation, and time to surgery), history of diabetes [type 1 or 2, year of diagnosis, treatment, associated complications (micro- and macroangiopathy, neuropathy)], cardiovascular comorbidities, smoking, previous foot ulcers or surgery, previous vascular surgery or angioplasty), information about the index foot ulcer [location, type, duration of symptoms, comorbidities (neuropathy, deformities, etc.)], the type of surgery performed (when applicable), and the number of surgical revisions. When relevant, information on antibiotic therapy and the results of bacteriologic samples were reviewed. Results of paraclinical examinations also retrieved, and they included C-reactive protein, leukocyte count, and glycated haemoglobin level), recent radiographs and arterial Doppler ultrasonography of the lower limbs. If the Doppler ultrasonography was abnormal, transcutaneous oxygen pressure measurement $\left(\mathrm{TcPO}_{2}\right)$ would be performed. The global severity of the lesions would be assessed using the International Working Group for Diabetic Foot (IWGDF) classification $^{13}$.

All the data were recorded using a Microsoft ${ }^{\circledR}$ Excel spreadsheet. Descriptive analysis was performed and described using mean and standard deviation (SD). The quantitative variables were compared using the MannWhitney test. Qualitative variables were compared using the Chi-square test. Statistical significance was defined at the $5 \%(\mathrm{p} \leq 0.05)$ level.

This study was conducted according to the principles of the world medical association declaration of Helsinki on ethical principles for medical research involving human subjects.

\section{RESULTS}

In the retrospective group, there were 23 patients (16 men, $70 \%$ ) aged 72 years ( \pm 13 years, range 49 to 94 ), and all of them received surgical treatment. In the prospective group, there were 28 patients $(22$ men, $79 \%)$ aged 67 years $( \pm 13$ years, range 26 to 93$)$, and only $22(79 \%)$ of them had 
Table I: Population characteristics

\begin{tabular}{|c|c|c|c|}
\hline & $\begin{array}{c}\text { Retrospective group } \\
(n=23)\end{array}$ & $\begin{array}{l}\text { Prospective group } \\
(n=22)\end{array}$ & $\begin{array}{c}\text { Statistical } \\
\text { significance }\end{array}$ \\
\hline \multirow[t]{2}{*}{ Age } & $72 \pm 13$ & $67 \pm 13$ & \\
\hline & (range 49 to 94 ) years & (range 26 to 93 ) years & \\
\hline Gender Male & $16(70 \%)$ & $22(79 \%)$ & \\
\hline Duration of diabetes & $16 \pm 9$ (range 1 to 30$)$ years & $21 \pm 11$ (range 3 to 39 ) years & $P=0.13$ \\
\hline Type 1 & $2(9 \%)$ & $2(10 \%)$ & \\
\hline Type 2 & $21(91 \%)$ & $20(90 \%)$ & \\
\hline Glycated Hemoglobin & $8.13 \% \pm 1.7$ (range 5.8 to 12$)$ & $8.9 \% \pm 2.8($ range 5.7 to 16$)$ & $P=0.30$ \\
\hline $\mathrm{HBP}^{\mathrm{a}}$ & $21(94 \%)$ & $13(61 \%)$ & $P<0.05$ \\
\hline Dyslipidemia & $18(80 \%)$ & $11(50 \%)$ & $P=0.11$ \\
\hline Active or past smoking & $12(52 \%)$ & $9(40 \%)$ & $P=0.36$ \\
\hline Cardiopathy ${ }^{\mathrm{b}}$ & $17(75 \%)$ & $14(64 \%)$ & $P=0.54$ \\
\hline Nephropathy ${ }^{c}$ & $14(62 \%)$ & $10(45 \%)$ & $P=0.24$ \\
\hline Retinopathy & $19(82 \%)$ & $12(54 \%)$ & $P=0.56$ \\
\hline Arteriopathy $^{d}$ & $17(75 \%)$ & $10(45 \%)$ & $P=0.05$ \\
\hline Neuropathy & $20(87 \%)$ & $17(78 \%)$ & $P=0.41$ \\
\hline Chronic wound history ${ }^{\mathrm{e}}$ & $13(55 \%)$ & $12(54 \%)$ & $P=0.49$ \\
\hline Previous amputation & $12(48 \%)$ & $10(45 \%)$ & $P=0.64$ \\
\hline IWGDF Score & 2.05 & 2.51 & $P=0.13$ \\
\hline
\end{tabular}

a Defined as chronic blood pressure over $130 / 80 \mathrm{mmHg},{ }^{\mathrm{b}}$ Cardiac insufficiency or myocardial ischemia, 'Defined by serum creatinine over $180 \mu \mathrm{mole} / \mathrm{l}$ or renal transplantation, ${ }^{\mathrm{d}}$ Defined as previous vascular surgery or intermittent claudication or previous vascular gangrene or abnormal vascular Doppler or Transcutaneous oxygen pressure $<30 \mathrm{~mm} \mathrm{Hg}$ or ankle-brachial index $<0,9$, e Previous chronic wound occurring more than three months

Table II: First surgical procedure

\begin{tabular}{|c|c|c|}
\hline & Retrospective group $(n=23)$ & Prospective group $(n=22)$ \\
\hline Soft tissues surgery without VAC-therapy & $\begin{array}{l}2 \text { Cases }(13 \%) \\
1 \text { heel bedsore } \\
1 \text { leg bedsore }\end{array}$ & 4 Cases $(18 \%)$ \\
\hline Soft tissues surgery with VAC-therapy & $\begin{array}{c}2 \text { Cases }(13 \%) \\
1 \text { hematoma draining } \\
1 \text { heel bedsore }\end{array}$ & \\
\hline \multirow[t]{6}{*}{ Partial or complete toe amputation } & 2 Cases $(8.6 \%)$ & 5 Cases $(23 \%)$ \\
\hline & 1st ray : 1 & 1 st ray : 2 \\
\hline & 2 nd ray : 0 & 2 nd ray : 1 \\
\hline & 3rd ray : 1 & 3rd ray : 0 \\
\hline & 4th ray : 0 & 4th ray : 1 \\
\hline & 5 th ray : 0 & 5th ray : 1 \\
\hline Ray amputation & 6 Cases $(26.3 \%)$ & 4 Cases $(18 \%)$ \\
\hline \multirow[t]{5}{*}{ (metatarsal + toe) } & 1st ray : 3 & 1st ray : 1 \\
\hline & 2 nd ray : 0 & 2 nd ray : 1 \\
\hline & 3rd ray : 0 & 3rd ray : 0 \\
\hline & 4th ray : 1 & 4th ray : 0 \\
\hline & 5 th ray : 2 & 5th ray : 2 \\
\hline Transmetatarsal amputation & 8 Cases $(34.8 \%)$ & 2 Cases $(9 \%)$ \\
\hline Transtibial amputation & 1 Case $(4.3 \%)$ & 5 Cases $(23 \%)$ \\
\hline
\end{tabular}

VAC: Vacuum-assisted closure

Table III: Main results

\begin{tabular}{|lccc|}
\hline & $\begin{array}{c}\text { Retrospective group } \\
(\mathbf{n = 2 3 )}\end{array}$ & $\begin{array}{c}\text { Prospective group } \\
\text { ( } \mathbf{n = 2 2 )}\end{array}$ & $\begin{array}{c}\text { Statistical } \\
\text { significance }\end{array}$ \\
\hline Global revision rate & $39 \%$ (9 cases) & $14 \%$ (3 cases) & $\mathrm{P}=0.05$ \\
Number of surgeries by patient & $1.9 \pm 0.9$ (range 1 to 7) & $1.15 \pm 0.4$ (range 1 to 2) & $\mathrm{P}<0.02$ \\
Amputation rate & $74 \%$ (17 cases) & $73 \%$ (16 cases) & $\mathrm{P}=0.93$ (ns) \\
Revision rate after amputation & $31 \%$ (5 cases) & $14 \%$ (3 cases) & $\mathrm{P}=0.48$ (ns) \\
\hline
\end{tabular}




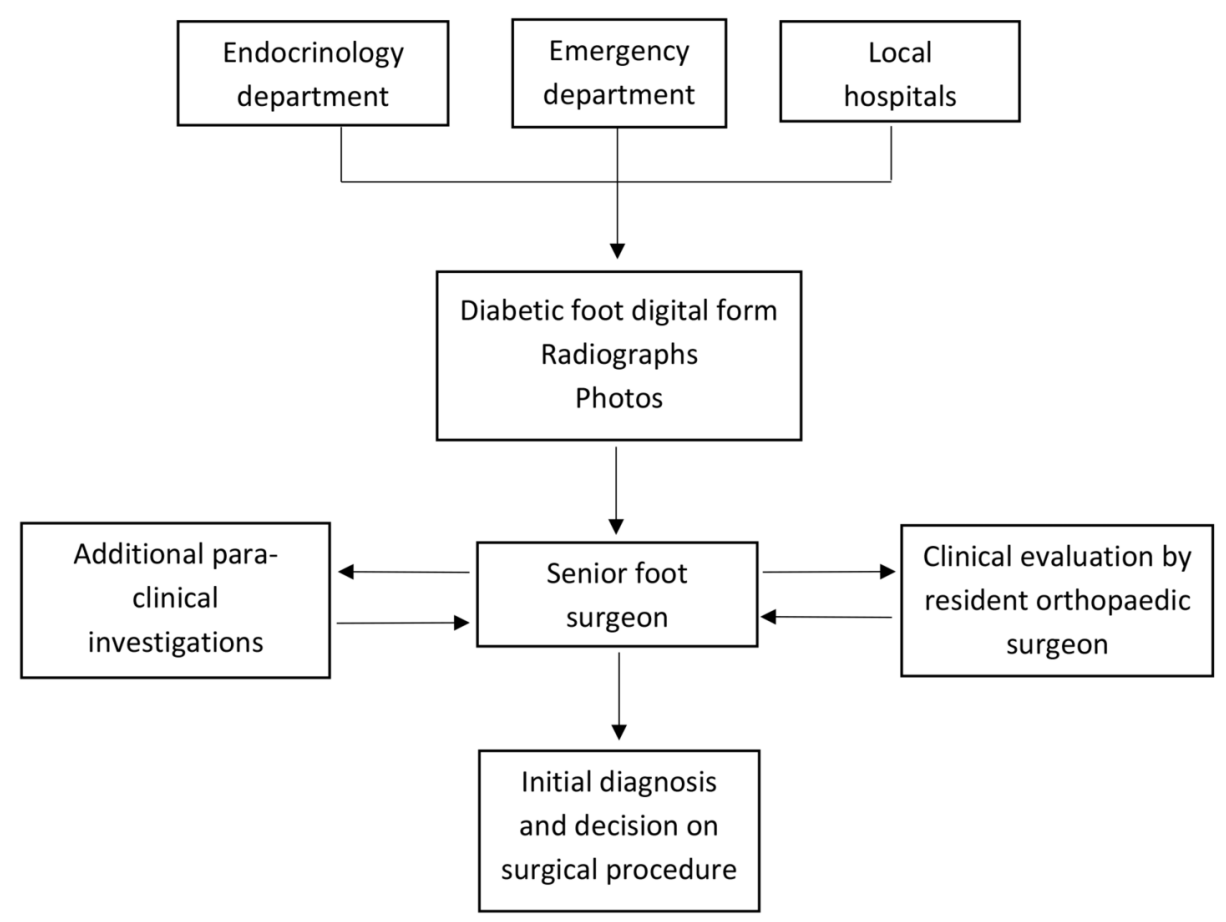

Fig. 1: Flow chart for diabetic foot management pathway.

surgical treatment (Table I). The two groups were comparable for age, gender, duration of diabetes, glycated haemoglobin level, cardiovascular comorbidities [except for hypertension, which was significantly higher in retrospective group (94 versus $61 \%, p<0.05$ )], and general diabetes complications (cardiopathy, nephropathy, and retinopathy). Diabetic foot history was not different except for the rate of arteriopathy, where it was significantly lower in the prospective group ( $43 \%$ vs $75 \%, \mathrm{p}=0.05)$. There was no difference in the history of chronic wounds or previous amputation procedures; nor was global severity of the diabetic foot based on the IWGDF score).

In both groups, the main lesion was diabetic foot ulcer (70\%). Sequence data were only available for the prospective group (Fig. 3). The mean time to admission was 35 days. Only $37 \%$ of the patients were able to put a date on the beginning of the wound. The mean time from admission to surgery was 16 days, and the mean interval between surgical opinion request and definitive recommendation was 3.2 days $(0-10)$.

Global amputation rate was similar in both groups: 17 of the 23 patients (74\%) in the retrospective group versus 16 of the 22 patients $(73 \%)$ in the prospective group (Table II). The amputation level varied between the two groups. Revision surgery were needed for $9(39 \%)$ patients in the retrospective group versus $3(14 \%)$ in the prospective group $(\mathrm{p}=0.05)$ (Table III). Mean revision rate was significantly lower in the prospective group $(1.15 \pm 0.4)$ compared to the retrospective group $(1.9 \pm 0.9)(p<0.02)$. In the retrospective group, 5 of 16 limbs (31\%) underwent more proximal amputation, and 4 needed vacuum-assisted closure (VAC) wound management, while in the prospective group, only 3 of the 22 limbs (14\%) underwent more proximal amputation. He difference was however not statistically significant.

\section{DISCUSSION}

Implementation of a clear management pathway has resulted in the improvement in surgical outcome for diabetic foot. We observed a decrease in revision rate after surgical procedures for diabetic foot pathology. Implementation of the pathway did not significantly change the indications for surgery, including the rates of amputation.

Medical literature has shown that multidisciplinary approach in the management of diabetic foot was able to reduce the rates of amputation ${ }^{17-19}$, cost of treatment, and improve the quality of life, even in non-urgent procedures for Charcot foot arthropathy ${ }^{20,2} 1$. A 9-year retrospective study on 648 patients with diabetic foot ulcers showed significant decrease in the frequency of major amputation after the introduction of a multidisciplinary team ${ }^{22}$. Implementation of collaboration between surgical and medical teams has been less often described, particularly concerning specific tools that can be used ${ }^{23}$.

The first limitation of this study is its lack of statistical power, due to the small number of patients. Moreover, part of information was collected retrospectively. We were not able to compare the severity of the ulcers since we did not have the description for all the ulcers. The two groups were 


\section{DIABETIC FOOT FORM}

transmitted by e mail to J.L.B. *

\section{A. IDENTIFICATION}

Name:

Date of birth:

Gender:

Unit:

Name of the doctor requesting surgical opinion:

Date of the request:

\section{B. DIABETIS and its COMPLICATIONS}

\section{1 - Diabetes:}

Beginning:

Type: $\square$ Type $1 \square$ Type 2 oral treatment $\square$ Type 2 insuline treatment

Glycated $\mathrm{Hb}$ (date): \%

Size: $\mathrm{cm} \quad$ Weight: $\mathrm{kg} \quad$ B.M.I.:

2 - Vascular risk factors $\square$ Yes $\square$ No

High blood pressure $(>130 / 85 \mathrm{mmHg}) \quad \square$ Yes $\square$ No

Known hyperlipidemia $\quad \square$ Yes $\square$ No

Smoking $\quad \square$ Yes $\square$ No Packs/day: for:

Obesity $\quad \square$ Yes $\square$ No

3-General complications $\square$ Yes $\square$ No If yes, circle the following

Nephropathy:

Creatininemia: CCR:

Kidney transplant, dialysis, Creatininemia $>180$

\section{Ocular:}

Cardiac: Specify:

Immunodepression:

Graft, long-course corticosteroids

Psychosocial disorder:

Social isolation, alcohol abuse, age $>80 y$, dementia

\section{DIABETIC FOOT HISTORY}

\section{1 - HISTORY}

Foot ulcers: (chronic if $>3 \mathrm{~m}$ ) $\quad \square$ Yes $\square$ No

$\square$ Right $\square$ Left $\square$ Bilateral

Dates:

Amputation: $\square$ No

$\square$ partial toe $\square$ total toe $\square$ ray $\square$ transmetatarsal

$\checkmark$ midfoot $\square$ calcanectomy $\square$ transtibial

$\square$ transfemoral

Comments (date, side):

Vascular surgery: $\square$ No

$\square$ femoro popliteal bypass $\square$ distal foot bypass

$\square$ stenting $\square$ sympatectomy

Comments (date, side):

\section{2- FOOT COMPLICATIONS}

Arteriopathy.

$\square$ Yes $\square$ No

Neuropathy:

$\square$ Yes $\square$ No

Charcot's neuroarthropathy:

Hyperkeratosis:

$\square$ Yes $\square$ No

Morphostatic disorder: $\quad \square$ Yes $\square$ No

Intertrigo:

$\square$ Yes $\square$ No

\section{INDEX ULCER}

\section{1 - ULCER REQUIRING ORTHOPAEDIC SURGEON OPINION}

Side: $\square$ Right $\square$ Left $\square$ Bilateral

Category: $\square$ Acute foot $\square$ Chronical ulcer

Location:

$\square$ Charcot foot $\square$ Other:

Ray:

Progression before opinion:

Comments:

Time between onset and request for surgical opinion:

Date of onset if foot ulcer: 


\section{2 - AVAILABLE PARACLINICAL DATA}

(Mandatory: Simple radiographies, recent arterial Doppler, if available TcP02 for chronical ulcer)

Standard X-ray (MANDATORY):

Should be repeated every 8-10 days to diagnose osteitis

NB: Include X-ray images

Date:

Conclusion:

$\square$ Normal $\square$ Osteitis $\square$ Charcot $\square$ Other

\section{Lower limb arterial echo Doppler:}

Date:

Conclusion:

$\square$ Normal $\square$ Local arteriopathy

$\square$ Diffuse arteriopathy $\square$ Thrombosis

$\square$ Other

\section{Transcutaneous 02 pressure (TcPo2):}

(Recommended for chronical ulcer) if $<30 \mathrm{~mm} \mathrm{Hg}$ request for vascular surgeon opinion before orthopaedic surgeon)

Date:

Conclusion: Supine position : $\mathrm{mm} \mathrm{Hg}$ Sitting position: $\mathrm{mm} \mathrm{Hg}$

Bacteriology: $\square$ Yes $\square$ No

Dates - sites - number:

Germs:

Antibiotherapy: $\square$ No $\square$ Oral $\square$ IV

Type:

Dose:

Duration:

Infectiologist's opinion: $\square$ Yes $\square$ No

Dr:

Date:

Conclusion:

Bone CT scan: (for suspected hindfoot osteitis) $\square$ Yes $\square$ No

Date:

Conclusion:

English version, the original form is in French (unpublished)

* J.L.B. : Senior surgeon specialised in foot surgery

Fig. 2: Diabetic foot form.
SCINTIGRAPHY + SPECT-CT (if doubt about osteitis):

$\square$ Double scintigraphy $\square$ No

Date:

Conclusion:

$\square$ Normal $\square$ Osteitis $\square$ Charcot $\square$ Other

MRI: (especially for acute foot ulcer with cellulitis)

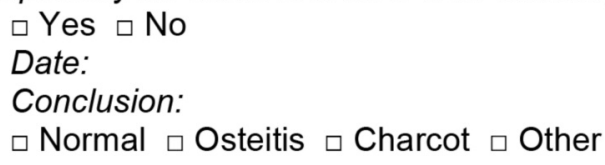

Angiography (or MRI if doubt and/or pathological Doppler - after vascular surgeon opinion)

Date:

Conclusion:

$\square$ Normal $\square$ Local arteriopathy

$\square$ Diffuse arteriopathy $\square$ Thrombosis

$\square$ Other

\section{Vascular surgeon opinion: \\ Name of the surgeon: \\ Comment:}

\section{Include recent photos of ulcer:}

\section{E. ORTHOPAEDIC SURGEON OPINION}

$1-$

Date:

Name:

Complementary assessment request:

First opinion:

2 -

Date:

Name:

Conclusion and final indication for treatment 


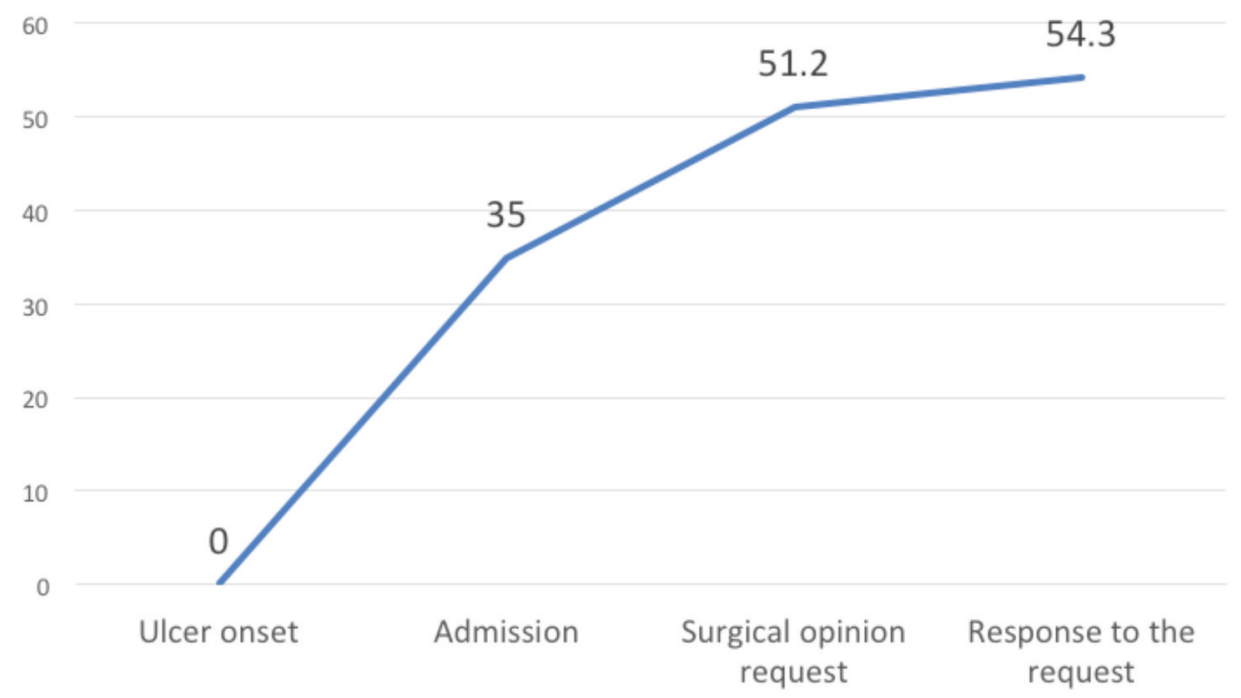

Fig. 3: Temporal data.

generally comparable except for the history of hypertension and rate of arteriopathy. This could be a potential bias that might favour the prospective group. However, we consider the additional vascular evaluation for patients in the prospective group a desirable consequence of implementing this management pathway.

The main aim of this study is to report the usefulness of a simple tool that can help to structure interdisciplinary management for patients with diabetic foot. This procedure is simple (needing only a text form) and easy to be shared with other practitioners. It is also inexpensive and time saving. It permits education of every medical and paramedical personnel involved in diabetic foot management. Rigor is essential in the management of diabetic foot. Decision on surgical treatment can be made based on information that is available on a single document, and collaboration with other medical and paramedical teams can be easily organised. Furthers studies should be done to evaluate the long-term efficiency of this pathway.

\section{CONCLUSION}

Implementation of the management pathway has resulted in a decrease in revision rate after surgical procedures for diabetic foot, but the rate of amputation remained unchanged. The process will allow a better overview of the underlying pathology of every patient. Such a management pathway would ensure that all the basic clinical and paraclinical evaluations are conducted before we plan for surgical intervention.

\section{CONFLICT OF INTEREST}

The authors declare no potential conflicts of interest.

\section{REFERENCES}

1. Mandereau-Bruno L, Denis P, Fagot-Campagna A, Fosse-Edorh S. Prévalence du diabète traité pharmacologiquement et disparités territoriales en France en 2012 / Prevalence of people pharmacologically treated for diabetes and territorial variations in France in 2012. Bull Epidemiol Hebd (Paris). 2014; (30-31): 493-9.

2. Ministry of Health Malaysia. The National Health and Morbidity Survey 2015 (NHMS 2015) Vol II: Non-Communicable Diseases, Risk Factors and Other Health Problems. Malaysia: Institute for Public Health, National Institutes of Health, Ministry of Health Malaysia; 2015. 291 p. MOH/S/IKU/52.15 (RR)

3. Geiss LS, Wang J, Cheng YJ, Thompson TJ, Barker L, Li Y, et al. Prevalence and incidence trends for diagnosed diabetes among adults aged 20 to 79 years, United States, 1980-2012. JAMA. 2014; 312(12): 1218-26. doi: 10.1001/jama.2014.11494

4. Ministry of Health Malaysia. Clinical Practice Guidelines on Management of Diabetic Foot Second Edition. Malaysia: Malaysian Health Technology Assessment Section (MaHTAS); 2018. 58 p. MOH/P/PAK/411.18(GU)-e 
5. Levine SE, Myerson M. Foot and Ankle Disorders. Philadelphia: WB Saunders; 2000. Management of ulceration and infection in the diabetic foot; $\mathrm{p}$ 413-38.

6. Singh N, Armstrong DG, Lipsky BA. Preventing foot ulcers in patients with diabetes. JAMA. 2005; $293(2)$ : $217-28$. doi:10.1001/jama.293.2.217

7. Prompers L, Huijberts M, Apelqvist J, Jude E, Piaggesi A, Bakker K, et al. High prevalence of ischaemia, infection and serious comorbidity in patients with diabetic foot disease in Europe. Baseline results from the Eurodiale study. Diabetologia. 2007; 50(1): 18-25. doi: 10.1007/s00125-006-0491-1

8. Wang AH, Xu ZR, Ji LN, Diabetics with Amputation Study Group Chinese Diabetes Society, China. [Clinical characteristics and medical costs of diabetics with amputation at central urban hospitals in China]. Zhonghua Yi Xue Za Zhi. 2012; 92(4): 224-7.

9. Fosse S, Hartemann-Heurtier A, Jacqueminet S, Ha Van G, Grimaldi A, Fagot-Campagna A. Incidence and characteristics of lower limb amputations in people with diabetes. Diabet Med. 2009; 26(4): 391-6. doi: 10.1111/j.1464-5491.2009.02698.x

10. Kow RY, Low CL, Ruben JK, Zaharul-Azri MZ, Lim BC. Predictive Factors of Major Lower Extremity Amputations in Diabetic Foot Infections: A Cross-sectional Study at District Hospital in Malaysia. Malays Orthop J. 2019; 13(3): 45-52. doi: 10.5704/MOJ.1911.008

11. Allahabadi S, Haroun KB, Musher DM, Lipsky BA, Barshes NR. Consensus on surgical aspects of managing osteomyelitis in the diabetic foot. Diabet Foot Ankle. 2016; 7: 10.3402/dfa.v7.30079. doi: 10.3402/dfa.v7.30079

12. Lipsky BA, Berendt AR, Cornia PB, Pile JC, Peters EJG, Armstrong DG, et al. 2012 Infectious Diseases Society of America clinical practice guideline for the diagnosis and treatment of diabetic foot infections. Clin Infect Dis. 2012; 54(12): e132-73. doi: $10.1093 / \mathrm{cid} / \mathrm{cis} 346$

13. Lipsky BA, Aragón-Sánchez J, Diggle M, Embil J, Kono S, Lavery L, et al. IWGDF guidance on the diagnosis and management of foot infections in persons with diabetes. Diabetes Metab Res Rev. 2016; 32 Suppl 1: 45-74. doi: 10.1002/dmrr.2699

14. Sagray BA, Malhotra S, Steinberg JS. Current therapies for diabetic foot infections and osteomyelitis. Clin Podiatr Med Surg. 2014; 31(1): 57-70. doi: 10.1016/j.cpm.2013.09.003

15. Acar E, Kacira BK. Predictors of Lower Extremity Amputation and Reamputation Associated With the Diabetic Foot. $J$ Foot Ankle Surg. 2017; 56(6): 1218-22. doi: 10.1053/j.jfas.2017.06.004

16. Besse JL, Leemrijse T, Deleu PA. Diabetic foot: the orthopedic surgery angle. Orthop Traumatol Surg Res. 2011; 97(3): 314-29. doi: 10.1016/j.otsr.2011.03.001

17. Frykberg RG, Zgonis T, Armstrong DG, Driver VR, Giurini JM, Kravitz SR, et al. Diabetic Foot Disorders: A Clinical Practice Guideline (2006 Revision). J Foot Ankle Surg. 2006; 45(5 Suppl): S1-66. doi: 10.1016/S1067-2516(07)60001-5

18. Bakker K, Apelqvist J, Schaper NC, International Working Group on the Diabetic Foot Editorial Board. Practical guidelines on the management and prevention of the diabetic foot 2011. Diabetes Metab Res Rev. 2012; 28 Suppl 1: 225-31. doi: 10.1002/dmrr.2253

19. Apelqvist J, Bakker K, van Houtum WH, Schaper NC, International Working Group on the Diabetic Foot (IWGDF) Editorial Board. Practical guidelines on the management and prevention of the diabetic foot: based upon the International Consensus on the Diabetic Foot (2007) Prepared by the International Working Group on the Diabetic Foot. Diabetes Metab Res Rev. 2008 ; 24 Suppl 1: S181-7. doi: 10.1002/dmrr.848

20. DiDomenico L, Flynn Z, Reed M. Treating Charcot Arthropathy Is a Challenge: Explaining Why My Treatment Algorithm Has Changed. Clin Podiatr Med Surg. 2018; 35(1): 105-21. doi: 10.1016/j.cpm.2017.08.012

21. Ramanujam CL, Stapleton JJ, Zgonis T. Diabetic charcot neuroarthropathy of the foot and ankle with osteomyelitis. Clin Podiatr Med Surg. 2014; 31(4): 487-92. doi: 10.1016/j.cpm.2013.12.001

22. Wang C, Mai L, Yang C, Liu D, Sun K, Song W, et al. Reducing major lower extremity amputations after the introduction of a multidisciplinary team in patient with diabetes foot ulcer. BMC Endocr Disord. 2016; 16: 38. doi: 10.1186/s12902-016-0111-0

23. Wu T, Chaer RA, Society for Vascular Surgery Young Surgeons Committee, Salvo NL, American Podiatric Medical Association Young Physicians' Leadership Panel. Building Effective Partnerships Between Vascular Surgeons and Podiatric Physicians in the Effective Management of Diabetic Foot Ulcers. J Am Podiatr Med Assoc. 2016; 106(4): 308-11. doi: 10.7547/15-062 